\title{
Coccidioidomycosis Causing Hydrocephalus
}

\author{
Mani Maheshwari ${ }^{1}$, Shashikala Ameneni ${ }^{2}$, Hemanthkumar Athiraman ${ }^{1}$ \\ 1. Hospital Medicine, Banner Health, Mesa, USA 2. Infectious Disease, Banner Health, Mesa, USA \\ Corresponding author: Hemanthkumar Athiraman, hkathiraman@gmail.com
}

Review began 01/29/2022 Review ended 01/31/2022 Published 02/03/2022

๑) Copyright 2022

Maheshwari et al. This is an open access article distributed under the terms of the Creative Commons Attribution License CCBY 4.0., which permits unrestricted use, distribution, and reproduction in any medium, provided the original author and source are credited.

\begin{abstract}
Coccidoidomycosis is caused by Coccidoides imitis and C. posadasii infection. Coccidioidomycosis is also known as San Joaquin Valley fever or desert rheumatism. It is only seen in the Southwest United States (Arizona, New Mexico, California, Texas, Nevada, and Utah), and Central and South America. This infection is acquired by the inhalation of fungal spores in the air. The most severe extrapulmonary coccidioidomycosis is coccidioidomycosis meningitis, in which patients present with headaches, photophobia, altered mental status, and hearing difficulties. This is a case report of a person with disseminated coccidioidomycosis meningitis complicated by hydrocephalus, presenting as a headache.
\end{abstract}

Categories: Internal Medicine, Infectious Disease, Neurosurgery

Keywords: immunocompromised patient, evd, desert rheumatism, san joaquin valley fever, coccidioidomycosis

\section{Introduction}

Coccidioides immitis and C. posadasii are coccidioidomycosis-causing dimorphic fungi found in the Southwestern United States and in Central and South America [1]. There is a lack of awareness regarding coccidioidomycosis in these endemic areas, and it is often missed, although about $30 \%$ of communityacquired pneumonia cases are due to coccidioidomycosis [2,3]. Coccidioidomycosis is at times managed supportively. The decision to treat rests on many factors, including disease severity, imaging findings, anticomplementary titers, immunosuppression or immunocompromised state, comorbidities [1]. The risk factors for disseminated coccidioidomycosis are immunosuppression, African or Filipino descent, and pregnancy [4]. There are about 150,000 coccidioidomycosis infections every year, with about 150 of these infections going on to disseminate into coccidioidomycosis meningitis [5].

This case report describes the most lethal type of disseminated coccidioidomycosis, meningitis, in a patient with latent tuberculosis and hepatitis $\mathrm{C}$ infection, both of which had not been treated. It is diagnosed using lumbar puncture/spinal tap, with cerebrospinal fluid analysis showing elevated WBC with lymphocytic pleocytosis, high protein, low glucose, and positive coccidioidomycosis serology with complementary fixation titers [6]. Titers of less than 1:16 indicate past infection or self-limited disease, and more than 1:16 indicates disseminated infection [7].

\section{Case Presentation}

A 39-year-old incarcerated male with a past medical history of hepatitis C, asthma, hypercholesterolemia, and posttraumatic stress disorder presents with three months of headache and pre-syncope without prior workup. He states that the headache worsens when he eats, has intermittent photophobia, has blurry vision, and has difficulty focusing for 30 seconds. The patient's vital signs in the ER were as follows: blood pressure of $112 / 91 \mathrm{mmHg}$, heart rate of $72 \mathrm{bpm}$, respiratory rate of 18 breaths/min, pulse oximetry of $100 \%$ on room air, and an oral temperature of $36.9^{\circ} \mathrm{C}$. Laboratory assessment is shown in Table 1 . A chest X-ray shows no abnormalities. A CT scan of the head/brain/cervical spine shows hydrocephalus with obstruction at the cerebral aqueduct and a right upper lobe pulmonary nodule (Figure 1). The Glasgow Coma Scale score is 15. 


\section{Cureus}

\begin{tabular}{|lll|}
\hline Lab & Patient's result & Normal result/range \\
\hline White blood cell count $(\mathrm{K} / \mu \mathrm{L})$ & 8.9 & $4.0-11.0$ \\
Hemoglobin $(\mathrm{g} / \mathrm{dL})$ & 13.5 & $13.5-17.0$ \\
Hematocrit $(\%)$ & 41.5 & $40.0-53.0$ \\
Platelet $(\mathrm{K} / \mathrm{ML})$ & 408 & $130-450$ \\
Glucose $(\mathrm{mg} / \mathrm{dL})$ & 105 & $70-106$ \\
Blood urea nitrogen $(\mathrm{mg} / \mathrm{dL})$ & 7 & $8-25$ \\
Creatinine $(\mathrm{mg} / \mathrm{dL})$ & 0.54 & $0.60-1.50$ \\
Sodium $(\mathrm{mmol} / \mathrm{L})$ & 137 & $134-147$ \\
Aspartate transaminase $(\mathrm{U} / \mathrm{L})$ & 14 & $12-47$ \\
Alanine transaminase $(\mathrm{U} / \mathrm{L})$ & 22 & $5-60$ \\
\hline
\end{tabular}

TABLE 1: Laboratory assessment on admission

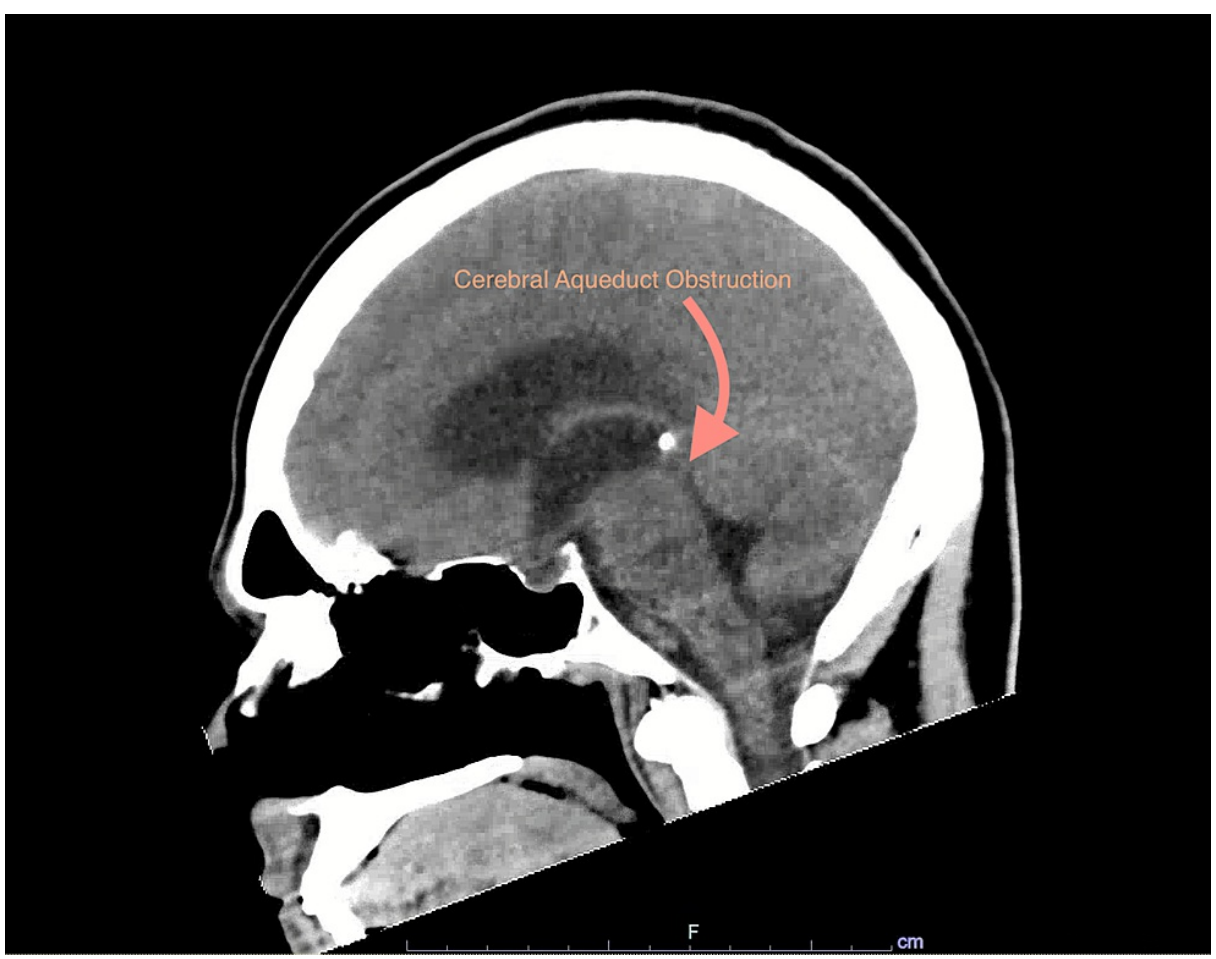

FIGURE 1: CT head/brain/cervical spine shows hydrocephalus with obstruction at cerebral aqueduct

The patient was admitted to the intensive care unit and empirically treated with IV acyclovir $700 \mathrm{mg}$ Q8h, IV amphotericin B $350 \mathrm{mg}$ Q24h, IV daptomycin $425 \mathrm{mg}$ Q24h, IV fluconazole $800 \mathrm{mg}$ Q24h, and IV meropenem $2 \mathrm{~g}$ Q8h. The results of the lumbar puncture/CSF analysis are shown in Table 2. 


\section{Cureus}

\begin{tabular}{|lll|}
\hline Cerebrospinal fluid lab & Patient's result & Normal result/range \\
\hline Spinal fluid color and character & Colorless and slightly hazy & Colorless and clear \\
White blood cell count & $553 / \mathrm{mm}^{3}$ & $0-5 / \mathrm{mm}^{3}$ \\
Red blood cell count & $120 / \mathrm{mm}^{3}$ & $0-10 / \mathrm{mm}^{3}$ \\
Neutrophils (\%) & 37 & $0-6$ \\
Lymphocytes (\%) & 16 & $40-80$ \\
Monocytes (\%) & 28 & $15-45$ \\
Glucose (mg/dL) & 14 & $40-70$ \\
Protein (mg/dL) & 583.0 & $15.0-40.0$ \\
\hline
\end{tabular}

\section{TABLE 2: Lumbar puncture results (CSF analysis)}

The patient declined neurologically, becoming more lethargic, disoriented, and unable to awaken. Interventional radiology was emergently consulted, and an external ventricular drain (EVD) was placed. The initial transduced ICP was $25 \mathrm{mmHg}$, and the drain was kept open at $10 \mathrm{mmHg}$. CSF was draining at 165 $\mathrm{mls} /$ day. The microbiology data results are shown in Table 3; positive for Coccidioides in the CSF, high West Nile Virus IgG in the CSF, and QuantiFERON-TB panel showing results consistent with latent tuberculosis.

\begin{tabular}{|lll|}
\hline Microbiology lab & Patient's result & Normal result/range \\
\hline Coccidioides EIA Ab, TP (typically IgM) & Positive & Negative \\
Coccidioides EIA Ab, CF (typically IgG) & Positive & Negative \\
Coccidioides IMDF Ab, IgM (TP) & Positive & Negative \\
Coccidioides IMDF Ab, IgG (CF) & Positive & Negative \\
Coccidioides Comp Fix & $1: 64$ & Negative \\
Cocci Comp Fix, CSF & $1: 32$ & Negative \\
HCV RNA, PCR, Quant (IU/mL) & $4,740,000$ & $<15 /$ not detected \\
HCV RNA, PCR, Quant (LogIU/mL) & 6.68 & $<1.18 /$ not detected \\
HSV 1 DNA, real-time PCR & Not detected & Not detected \\
HSV 2 DNA, real-time PCR & Not detected & Not detected \\
HIV 1/2 Ag/Ab screen (4th Gen) & Non-reactive & Non-reactive \\
West Nile Virus, IgG, CSF & 3.87 & Negative \\
West Nile Virus, IgM, CSF & $<0.90 /$ not detected & Not detected \\
\hline
\end{tabular}

TABLE 3: Microbiology data

The treatment regimen is tailored to the coccidioidomycosis meningitis/disseminated coccidioidomycosis infection, and the dose is increased to fluconazole $1,200 \mathrm{mg}$ IV daily. The patient did not tolerate EVD weaning/clamp with increasing CSF protein. The CSF protein values are shown in Figure 2. The gradual increase of CSF protein levels delayed ventriculoperitoneal (VP) shunt placement because, as per neurosurgery, a VP shunt can only be placed once CSF protein levels are less than 150 . 


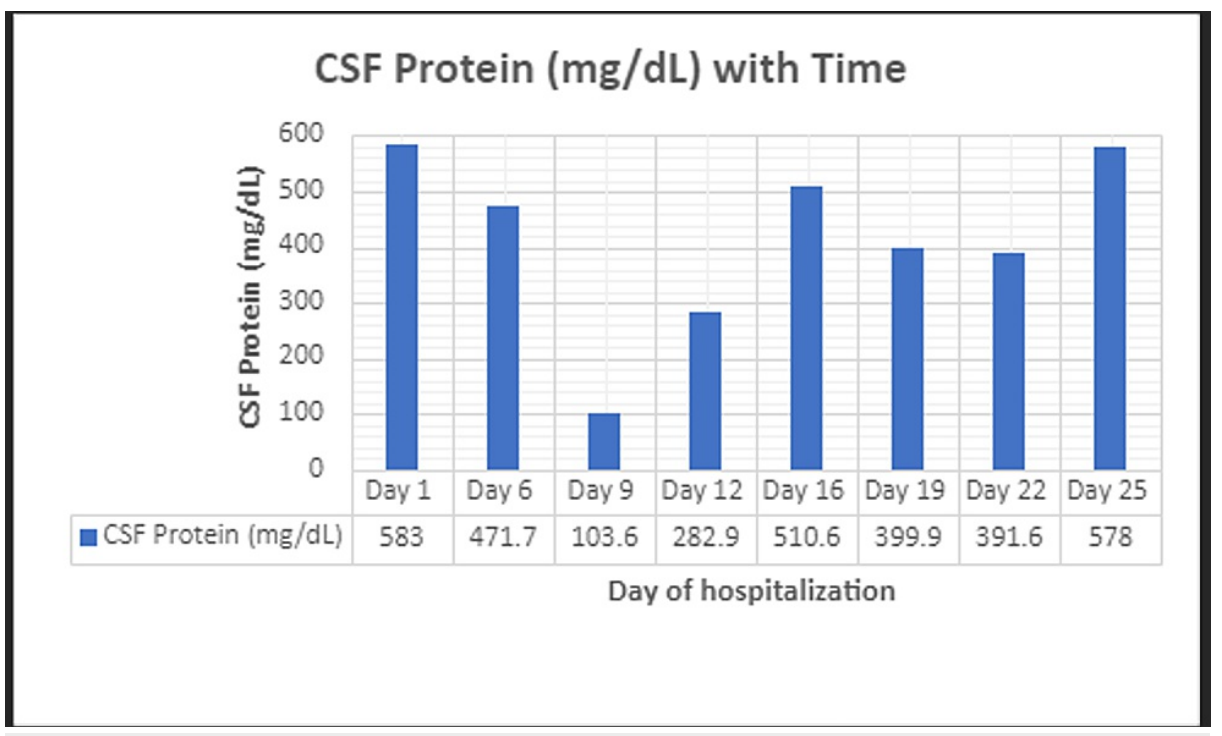

FIGURE 2: Cerebrospinal fluid protein (mg/dL) levels with time

\section{Discussion}

Coccidioidomycosis meningitis, if not treated, is universally fatal; $91 \%$ of patients will die within one year, and all patients will die within two years [8]. These numbers improve if patients are treated with azoles or Ambisome [9]. The guidelines suggest treating coccidioidomycosis meningitis with high-dose fluconazole, 800 to $1200 \mathrm{mg}$ daily. No trial has compared intrathecal Ambisome and high-dose fluconazole. Although there is a delay in the normalization of CSF studies after treatment with fluconazole, symptoms generally resolve within 4-8 months. The response to treatment is assessed by the improvement in clinical symptoms and decreased coccidioidomycosis complementary fixation titers [10].

The most common complications of cocci meningitis are hydrocephalus, CNS vasculitis, infarction, vasospasm, and hemorrhage. A VP shunt is necessary for patients with hydrocephalus [10]. Furthermore, a study by Dewsnup et al. states that disease is only suppressed in coccidioidomycosis meningitis patients who achieved remission during azole treatment [11].

For the patient in this case report, after 19 days of IV fluconazole, he complained of extensive pruritis and skin sloughing. The treatment was changed to IV voriconazole, $700 \mathrm{mg} \mathrm{Q12H}$, and the pruritis worsened. The treatment was changed to oral itraconazole $200 \mathrm{mg}$ every eight hours and intrathecal amphotericin 0.1 $\mathrm{mg}$ Q48h. EVD was maintained open at $5 \mathrm{mmHg}$, and CSF output increased to $218 \mathrm{mLs} / \mathrm{day}$. The gradual increase in CSF protein levels delayed VP shunt placement.

After 19 days of intrathecal amphotericin only, IV amphotericin $350 \mathrm{mg}$ Q24hrs was added to the regimen since CSF white blood cell count and protein levels increased. The patient continued to have headaches.

The patient was then re-challenged with voriconazole $450 \mathrm{mg}$ PO Q12h, and he tolerated it; at this point, itraconazole was discontinued. Serum and CSF coccidioidomycosis titers were checked weekly and trended down. Serum titers decreased from 1:64 to 1:16 over four weeks. CSF titers decreased from 1:64 to 1:1 over four weeks. Similarly, the CSF white blood cell count also started to trend down, and, subsequently, intrathecal Ambisome was discontinued. The EVD was clamped, and the repeat CT head was stable (no dilation of ventricles), allowing for the safe removal of the EVD.

The patient developed hallucinations, confusion, and acute transaminitis two days later due to voriconazole. Until the patient's mental status and liver function tests improved, voriconazole was held for the next seven days. Afterward, the patient was transitioned to oral voriconazole $300 \mathrm{mg}$ Q12h. Subsequently, he was cleared for discharge on IV Ambisome $350 \mathrm{mg}$ Q12h for four more weeks and voriconazole $300 \mathrm{mg}$ Q12h for life. More than 90 days after admission, he remains in the hospital on the same regimen.

\section{Conclusions}

It is vital to detect coccidioidomycosis infection in patients who have recently traveled to or live in endemic areas such as Arizona, New Mexico, California, Texas, Nevada, Utah, and parts of Central and South America. Delayed diagnosis leads to unnecessary healthcare utilization and costs, improved antibiotic stewardship, and prompt treatment of patients. If left untreated, coccidioidomycosis may be fatal. 


\section{Additional Information \\ Disclosures}

Human subjects: Consent was obtained or waived by all participants in this study. Conflicts of interest: In compliance with the ICMJE uniform disclosure form, all authors declare the following: Payment/services info: All authors have declared that no financial support was received from any organization for the submitted work. Financial relationships: All authors have declared that they have no financial relationships at present or within the previous three years with any organizations that might have an interest in the submitted work. Other relationships: All authors have declared that there are no other relationships or activities that could appear to have influenced the submitted work.

\section{References}

1. Stockamp NW, Thompson GR 3rd: Coccidioidomycosis. Infect Dis Clin North Am. 2016, 30:229-46. 10.1016/j.idc.2015.10.008

2. Donovan FM, Shubitz L, Powell D, Orbach M, Frelinger J, Galgiani JN: Early Events in Coccidioidomycosis . Clin Microbiol Rev. 2019, 33:10.1128/CMR.00112-19

3. Valdivia L, Nix D, Wright M, et al.: Coccidioidomycosis as a common cause of community-acquired pneumonia. Emerg Infect Dis. 2006, 12:958-62. 10.3201/eid1206.060028

4. Cayce WR: Cases from the aerospace medicine residents' teaching file. Case \#47. Primary pulmonary coccidioidomycosis. Aviat Space Environ Med. 1991, 62:1200-1202.

5. Blair JE, Ampel NM: Coccidioidal meningitis. UpToDate. Post TW (ed): UpToDate, Waltham; 2022.

6. Jackson NR, Blair JE, Ampel NM: Central nervous system infections due to coccidioidomycosis . J Fungi (Basel). 2019, 5:10.3390/jof5030054

7. Coccidioides antibody by CF. (2022). Accessed: January 31, 2022: https://td.aruplab.com/Tests/Pub/0050170.

8. Vincent T, Galgiani JN, Huppert M, Salkin D: The natural history of coccidioidal meningitis: VA-Armed Forces cooperative studies, 1955-1958. Clin Infect Dis. 1993, 16:247-54. 10.1093/clind/16.2.247

9. Johnson RH, Einstein HE: Coccidioidal meningitis. Clin Infect Dis. 2006, 42:103-7. 10.1086/497596

10. Coccidioidal meningitis. (2021). Accessed: November 28, 2021: https://health.ucdavis.edu/valleyfever/about-valley-fever/clinical-manifestations/coccidioidal-meningitis/index.html.

11. Dewsnup DH, Galgiani JN, Graybill JR, Diaz M, Rendon A, Cloud GA, Stevens DA: Is it ever safe to stop azole therapy for Coccidioides immitis meningitis?. Ann Intern Med. 1996, 124:305-10. 10.7326/0003-4819-124-3199602010-00004 